\title{
PERIPHERAL LOCATION OF THE Y CHROMOSOME: RELATIONSHIP TO RACE AND LENGTH HETEROMORPHISM
}

RAM S. VERMA, JORGE RODRIGUEZ, JYOTI V. SHAH AND HARVEY DOSIK Departments of Laboratories and Medicine, The Jewish Hospital and Medical Center of Brooklyn, and Department of Medicine, State University of New York Downstate Medical Center, Brooklyn, New York 11238

Received 10.vii.83

\section{SUMMARY}

In the present report we examined the position of the $\mathrm{Y}$ chromosome with respect to its size and race to determine their relationship to its peripheral location. Peripheral blood lymphocytes were cultured from 172 normal male individuals (70 Asian Indians; 49 American Blacks; and 53 Caucasians) and 2770 QFQ cells were photographed. The length of the $Y$ chromosome was classified into four groups i.e., small, average, large and very large as described earlier (Verma et al., J. Med. Genet., 15, 227-281, 1978). The average incidence of peripheral location of all races for small, average, large and very large was $3.64,5.84,10.51$ and 11.17 per cent respectively. For blacks and caucasians, the peripheral location was influenced by its size while the incidence remained the same for Indians for all sizes. Consequently, it is presumed that the position of the $\mathrm{Y}$ chromosome in somatic metaphases depends upon race as well as its size. Furthermore, we have provided a method for determining the position of the $\mathrm{Y}$ chromosome which should suffice for most situations.

\section{INTRODUCTION}

It has been proposed that the distribution of human chromosomes at somatic metaphase is not random. For example, acrocentric chromosomes (13-15, 21 , and 22) tend to lie closer together than would be expected by chance. Morishima et al. (1962) suggested that the late replicating X chromosome tends to be near the periphery while German (1962) disagreed with this conclusion. Furthermore some suggest that the $\mathrm{Y}$ chromosome is located peripherally more often than other chromosomes, while others disagree with this notion (Barton et al., 1965; Cohen et al., 1966; Gripenberg, 1964; Miller et al., 1963a, b; Ockey, 1969 and Spence et al., 1973; Sele et al., 1977). Similar controversy exists concerning the location of the autosomes. Barton et al. (1965) suggest that acrocentric chromosomes lie near the center of metaphase spreads, contradicting the earlier work of Miller et al. (1963b).

These conflicting claims are due to lack of a standard definition of "peripheral location" and lack of a method for recording the data. Potential bias may be introduced by selecting only circular spreads for study and using a small number of metaphases.

In this report we considered the location of the $\mathrm{Y}$ chromosome at somatic metaphase with respect to $Y q$ length heteromorphisms and race using subjectively defined criterias. We used a large sample size (2770 cells) from 172 normal male individuals (70 Asian Indians; 53 Caucasians and 49 
American blacks. Three different races have been added to include an additional factor. To our knowledge such an approach has not been taken before.

\section{MATERIALS AND METHODS}

One-hundred-and-seventy-two normal male individuals (70 Asian Indians; 53 Caucasians; and 49 American blacks) from three races were selected for this study. Lymphocytes from peripheral blood were cultured as usual. QFQ (Q-bands by fluorescence using quinacrine) technique was performed on the slide (Verma and Lubs, 1975; Verma and Dosik, 1976). Cells were photographed on tri X film using a Zeiss photomicroscope II. At least 20 cells from each individual were initially photographed. Recording of the location of the $\mathrm{Y}$ chromosome was performed directly by enlarging the metaphase onto a circle or square as shown in figs. 1 and 2 . If the metaphase spread was circular then fig. 1 was used and if the spread was square then fig. 2 was used to score the location of the Y. If a spread did not fit into either space then it was discarded. Each fig. was subdivided into 10 parts at a distance of $1 \mathrm{~cm}$. The following criteria was introduced to identify the location of the $\mathrm{Y}$ as either peripheral or non-peripheral. If, the $\mathrm{Y}$ chromosome fell in area \#10 and there was no other chromosome further from it, then it was noted to be peripheral. If it was not peripheral, location of the Y chromosome was also recorded. Only complete metaphases with 46 counts were included in the study.

A total of 2770 cells were selected for this purpose, and the exact location of the Y chromosome in each metaphase spread was determined. Furthermore the length of the Y chromosome was classified into 4 groups:

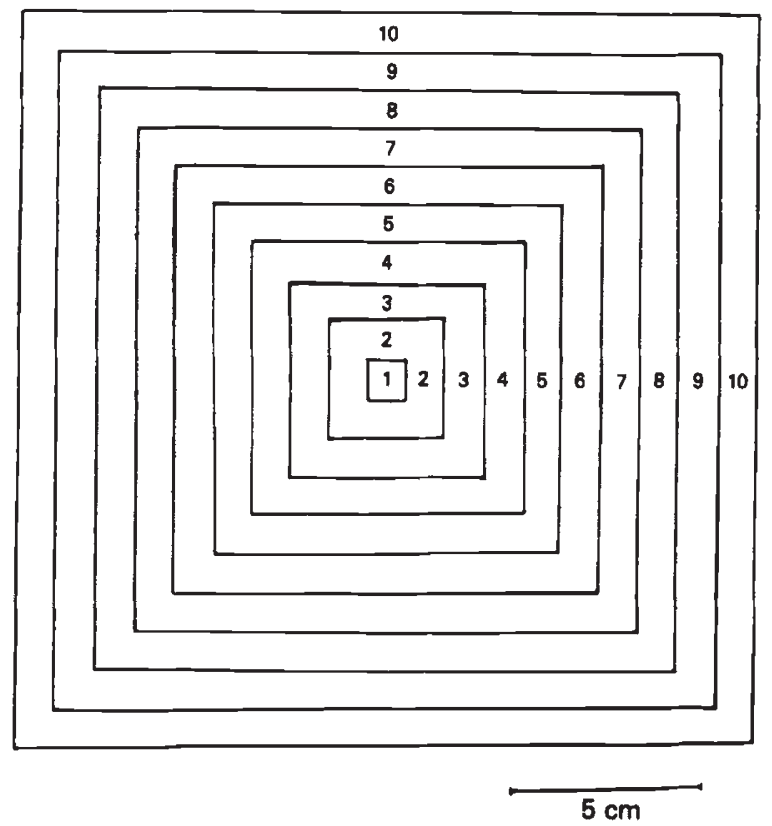

FIG. 1. Square used in localising the $Y$ chromosome. 


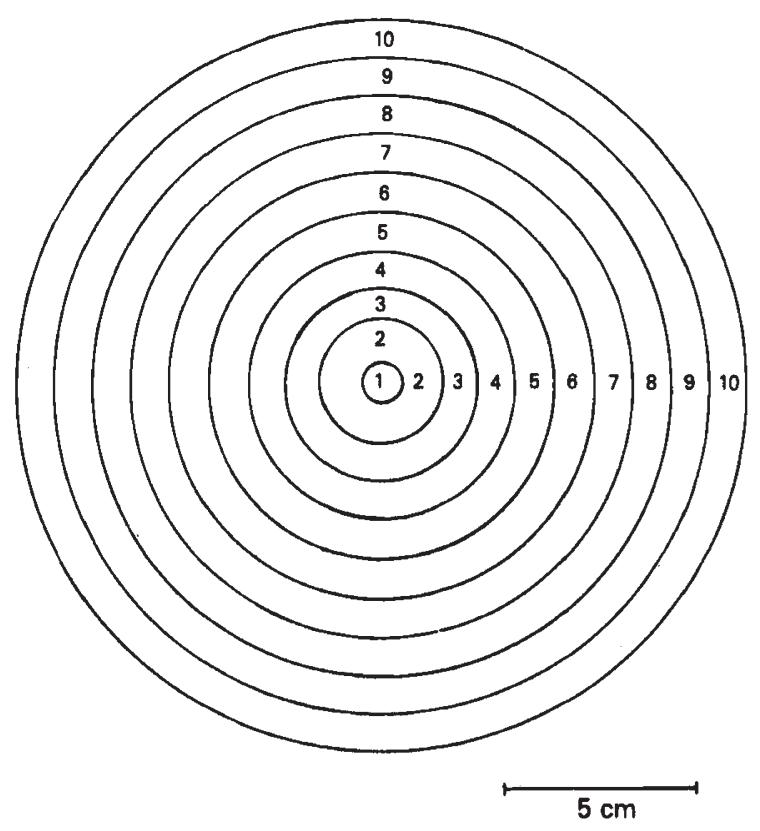

Fig. 2. Circle used in localising the Y chromosome.

small, average, large and very large with $\mathrm{Y} / \mathrm{F}$ indices of $0 \cdot 81-0 \cdot 94,0.94$ $1 \cdot 09,1 \cdot 1-1 \cdot 23$; and $>1 \cdot 23$ respectively. The logic behind this classification has been described elsewhere. (Verma et al., 1978). Double blind scoring was done with respect to the length of the $\mathrm{Y}$ chromosome. The length measurements were performed by one investigator while location was determined by another. Only after completion of the study, was the data compared.

In order to establish causal relationships, a correlation coefficient ( $r$ ) analysis was used to examine the degree to which two variables (i.e., length of Y-chromosome vs. incidence of peripheral location) vary together.

\section{RESUltS AND DISCUSSION}

The location of small, average, large and very large $Y$ chromosomes in metaphase spreads is classified in tables $1-4$. In table 5 size and race are compared. In table 6 all four sizes have been compared. One can see from table 6 that a specific increasing trend was noted. For example, when the $Y$ was small in size, only 3.64 per cent of the cells were peripherally located while very large $Y$ had 11.7 per cent, an increase of 306 per cent. Such a trend was not noted in other areas. Where one looked at peripheral location in relation to races, Indians had a greater number of $Y$ chromosomes located peripherally and size did not seem to play a role $(p>0.05)$. With blacks and Caucasians the peripheral location was found to be less common but size was more important $(p<0 \cdot 01)$. Based on these observations, we suggest that peripheral location of the $\mathrm{Y}$ chromosome may be influenced by its length and by race. Such an approach has not been taken before; therefore 


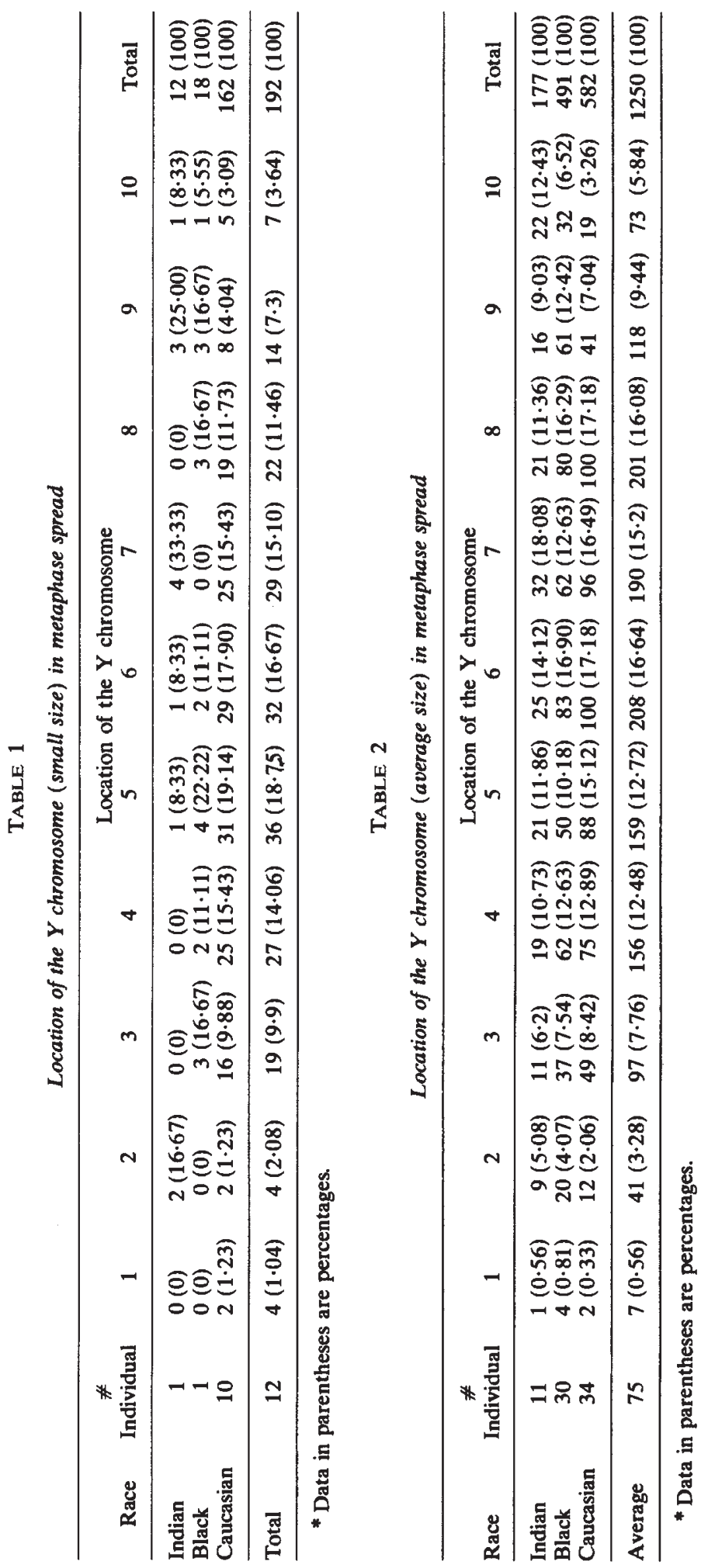



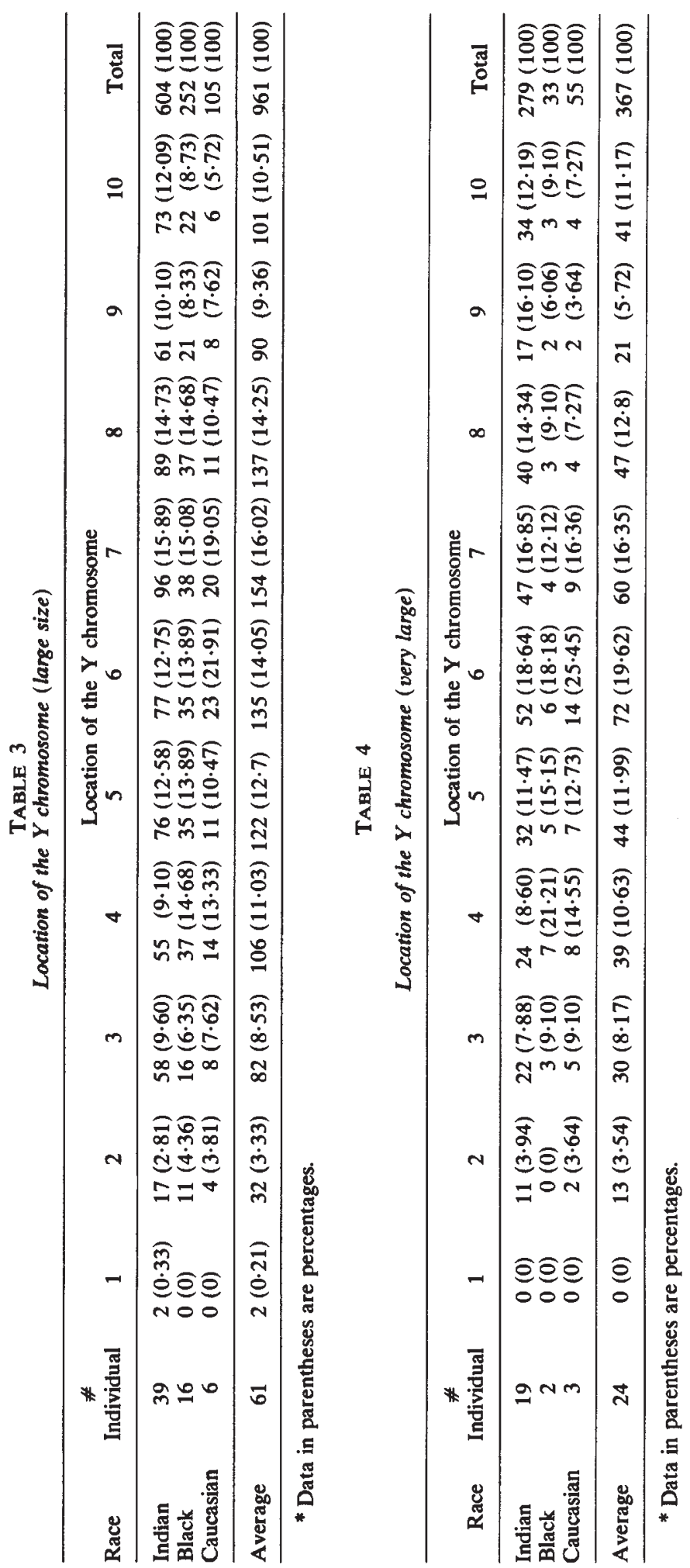

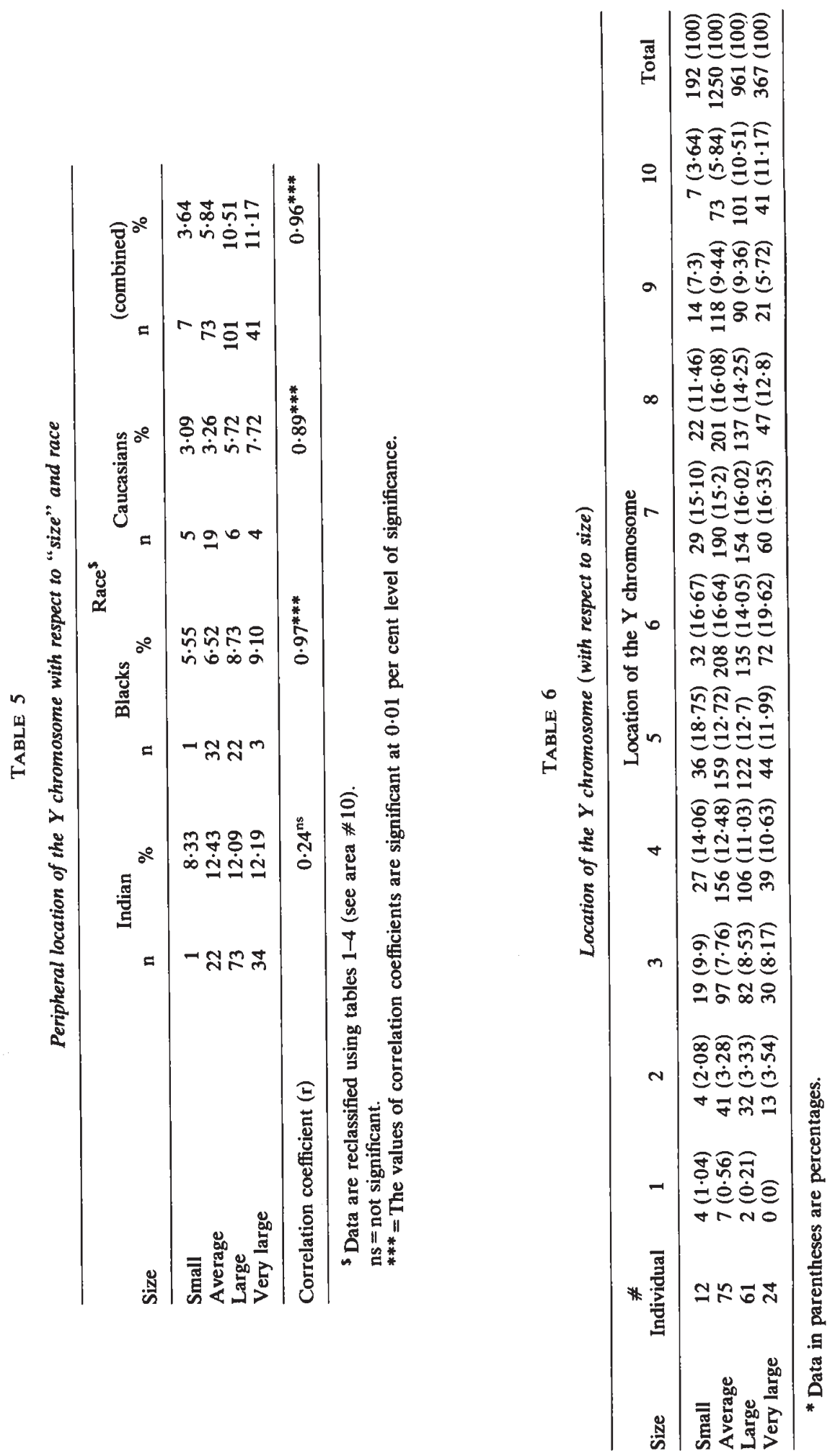
such an impression neither can be confirmed nor denied. However, location of the Y chromosome has been observed with respect to other chromosomes and its peripheral location has been suggested by some investigators (Miller et al., 1963; Gripenberg, 1964; Cohen et al., 1966; and Kowalski et al., 1978) while denied by other (Spence et al., 1973; and Sele et al., 1977).

The long arm of the $\mathrm{Y}$ chromosome is heterochromatic, with length heteromorphisms. The longer $\mathrm{Y}$ resulted from duplication of constitutive heterochromatic material (Arrighi and Hsu, 1971). The present study shows that these heterochromatic regions may play a role in the location of the $Y$ chromosome.

Schmidtke and Epplen (1980) have postulated that blocks of constitutive heterochromatin contribute to the non-random distribution of chromosomes at metaphase by preventing some of the pre-existing spatial relationships. In plants, Avivi and Feldman (1980) have strongly suggested that the arrangements of chromosomes in the interphase nucleus is influenced by nuclear polarity and other nuclear components and further they emphasised that ordered arrangement of chromosomes in the nucleus is under genetic control. Comings (1980) noted that constitutive heterochromatin is condensed onto the inner nuclear membrane on the periphery while genetically active chromatin occupies the more central position of the nucleus. Could this result in the peripheral location of $Y$, assuming $Y q 12$ is genetically inactive and late replicating? The longer $Y$ has a larger amount of heterochromatin and this may increase the incidence of its peripheral location as seen in table 6 . In conclusion, the long $\mathrm{Y}$ chromosome has a tendency to occupy a peripheral position in the metaphase suggesting the $\mathrm{Y}$ chromosome is not randomly distributed owing to its length heteromorphisms. We provided a method for scoring the so called peripheral location of the $\mathrm{Y}$. This simple approach should be useful in determining the position of the $\mathrm{Y}$ and other chromosomes in metaphase spreads.

\section{REFERENCES}

ARRIGHI, F. E. AND HSU, T. C. 1971. Localization of heterochromatin in human chromosome. Cytogenetics, $10,81-86$.

AVIVI, K. AND FELDMAN, M. 1980. Arrangements of chromosomes in the interphase nucleus of plants. Hum. Genet., 55, 281-295.

BARTON, D. E., DAVID, F. N. AND MERRINGTON, M. 1965. The relative position of the chromosomes in the human cell in mitosis. Ann. Hum. Genet., 29, 139-146.

COHEN, M. M., SHAW, M. W. AND MACLUER, J. W. 1966. Racial differences in the length of the human Y chromosome. Cytogenetics, 5, 34-52.

COMINGS, D. E. 1980, Arrangements of chromatin in the nucleus. Hum. Genet., 53, 131-143.

GERMAN, J. L. (1962). DNA Synthesis in human chromosomes. Trans. N.Y. Acad. Sci., 24, 395-407.

GRIPENBERG, U. 1964. Size variation and orientation of the human $Y$ chromosome. Chromosoma, 15, 618-629.

KOWALSKI, C: J., NASJLETI, C. E. AND SCHMITT, B. 1978. On the peripheral location of the Y chromosome. Hum. Genet., 44, 123-135.

MILLER, O. J., MUKHERJEE, B. B., BREG, W. R. AND VAN GAMBLE, A. 1963a. Non-random distribution of chromosomes in metaphase figures from cultured human leukocytes. I. The peripheral location of the Y chromocome. Cytogenetics, 2, 1-14.

MILLER, O. J., BREG, W. R., MUKHERJEE, B. D., VAN GAMBLE, A. AND CHRISTAKOS, A. C. $1963 \mathrm{~b}$. Non-random distribution of chromosomes in metaphase figures from cultured human leukocytes II. The peripheral location of chromosomes 13, 17-18 and 21 . Cytogenetics, 2, 152-168. 
MORISHIMA, A.. GRUMBACK. M. AND TAYLOR, J. H. 1962. Asynchronous duplication of human chromosomes and the origin of sex chromatin. Proc. Nat. Acad. Sci. (USA), 48, 756-763.

OCKEY, C. H. 1969. The positions of chromosomes at metaphase in human fibroblasts and their DNA Synthesis behavior. Chromosoma (Berlin), 27, 308-320.

SCHMIDTKE, J. AND EPPLEN, J. T. 1980. Sequence organization of animal nuclear DNA. Hum. Genet., 55, 1-18.

SELE, B., JALBERT, P., VAN CUTSEM, B., LUCAS, M., MOURIQUAND, C. AND BOUCHEZ, $R$. 1977. Distribution of human chromosomes on the metaphase plate using banding techniques. Hum. Genet., 39, 39-61.

SPENCE, M. A., FRANCKE, V. AND FORSTHE, A. B. 1973. Evidence against the peripheral location of the Y chromosome in human metaphase cells. Cytogenet cell. Genet., 12, 49-52.

Verma, R. S. AND LUBS, H. A. 1975. A simple R-banding technic. Am. J. Hum. Genet., 27, 110-117.

VERMA, R. S., DOSIK, H., SCHARF, T. AND LUBS, H. A. 1978. Length heteromorphisms of fluorescent (f) and non-fluorescent (nf segments of human $Y$ chromosome: Classification, frequencies and incidence in normal caucasians, $J$. Med. Genet., 15, 277-281.

VERMA, R. S. AND DOSIK, H. 1976. An improved method of photographing human fluorescent chromosomes. J. Microscopy, 108, 339-341. 